\title{
RASTROS: DIZENDO SOBRE OS FAZERES/DIZERES
}

\author{
Marisol Barenco CorrêA de Mello
}

\begin{abstract}
RESUMO: Com vistas ao aclaramento de noções erroneamente herdadas do contexto social e histórico da cultura moderna ocidental, que teve/tem como um de seus projetos o "apagamento" do sujeito, ou o distanciamento entre os sujeitos e suas formas de fazer, dizer, pensar, este artigo pretende contribuir com elementos para a construção de um outro paradigma nas ciências humanas. Trata-se de um relato sobre o processo de construção de nossa própria pesquisa, articulado à reflexão sobre as diversas formas de fazerdizer, que trabalharemos na forma de uma aproximação do processo possível, na academia, do relato do cineasta Walter Salles sobre o processo de construção do filme Central do Brasil. Como pressuposto fundamental, o resgate de uma visão que aproxima os sujeitos de seus fazeres-dizeres, na forma dos rastros que deixamos - que nos permitem resgatar de forma indiciária os processos - e legitimamos, como parte constitutiva dos fazeres-dizeres.
\end{abstract}

Palavras-chave: Rastros, linguagens, cultura, adultos não-alfabetizados, conhecimento.

Estas reflexões que aqui tecemos tiveram origem numa história anterior. Na realidade, na apresentação de nossa versão final da dissertação de Mestrado, à Universidade Federal Fluminense, na discussão que se estabeleceu com a banca examinadora, na ocasião da defesa. Um dos aspectos discutidos e ressaltados da nossa dissertação "A multiplicidade das formas de ser racional: Escrita e racionalidade" foi justamente o processo de sua construção, que foi mantido, na forma de rastros, na escrita final do trabalho. De maneira compatível com a perspectiva de Ginzburg,

\footnotetext{
* Este texto foi elaborado a partir da reflexão sobre o processo de construção da dissertação intitulada "A multiplicidade das formas de ser racional: Escrita e racionalidade", apresentada ao programa de Mestrado da Universidade Federal Fluminense, e aprovada em março de 1998.
}

**E-mail: marisol@ compuland.com.br. 
uma de nossas referências teórico-metodológicas, mantivemos na escrita final do trabalho as pistas reveladoras de nossos caminhos e descaminhos, das trilhas sinuosas e por vezes até sem saída que renovaram e impulsionaram para perspectivas inesperadas e promissoras. Assim sendo, por julgarmos que este tema raramente tem sido contemplado nas discussões acadêmicas sobre as metodologias dos trabalhos de pesquisa, é que buscamos então contribuir com estas reflexões, que assinalam a pertinência e a relevância de assumirmos o vínculo indissociável, na construção dos trabalhos de pesquisa, entre os fazeres e os dizeres.

\section{"Apaguem os rastros!" (Bertold Brecht)}

Se pudéssemos, numa expressão, definir o projeto da modernidade, Brecht a diria por nós. Desde o apagamento gradual dos percursos, na representação espacial, à pretensão do distanciamento máximo do sujeito, cinco séculos de cultura, no ocidente, nos legaram uma cosmovisão em que, em nome da clareza, da evidência, a transparência substituiu a opacidade da experiência.

A arte, lugar privilegiado revelador da cultura - pelo menos a hegemônica -, oferece-nos uma riqueza de indícios que nos possibilitam redesenhar esse movimento, que pretendeu "varrer" os vestígios dos sujeitos. Benjamin (1994, p. 117) oferece-nos esta reflexão, ao dizer sobre o quarto burguês, do século passado, com todo o seu "aconchego", e todos os traços e vestígios do habitante, sob forma de preciosidades pessoais, que ajustam o "interior" a uma subjetividade que habita, que forma pelo hábito um lugar povoado de sinais. Faz lembrar de Certeau (1994) e a descrição das casas habitadas pelos "espíritos" de seus moradores, na forma de objetos deixados no lugar onde foram largados, tornando viva, pelos vestígios da estada, a presença-ausência e história dos sujeitos.

A este "interior" povoado pelos espíritos visíveis através dos vestígios dos habitantes, Benjamin contrapõe a figura de Scheebart, em cujos romances seus sujeitos habitam casas de vidro, ajustáveis e móveis. Não há como deixar rastros no vidro, material liso e frio, onde nada se fixa. Como diz Benjamin, "As coisas de vidro não têm nenhuma aura. O vidro é em geral o inimigo do mistério". Mistério... Faz lembrar nossa leitura adolescente de Conan Doyle, e o mistério que nos remetia aos interiores dos recintos ingleses, cenários de crimes, que Holmes vasculhava, enquanto descrevia em detalhes a profusão dos vestígios, que contavam a história 
que o detetive lia, a partir dos indícios, dos pormenores negligenciados. Será possível haver essa aura nos edifícios de aço de Bauhaus?

Os rastros foram apagados e, com eles, a experiência foi tornada excesso, como aquilo a que se "limpa", pois os produtos valorizados são claros, transparentes, tanto mais evidentes quanto maior o distanciamento dos sujeitos, seus hábitos e, principalmente, seus percursos.

Herdeiros desta visão de mundo, aqui estamos nós, falando do lugar da produção do conhecimento, neste cenário que valoriza a transparência e onde os rastros são excessos a serem apagados, em nome da objetividade. Aqui começa nossa história, que na interação com essa cultura fez-se trabalho.

No universo acadêmico, como leitores, estamos acostumados com a aparência dos textos, ou seja, a forma com que estes se nos apresentam, em sua versão final. Daí a discrepância que encontramos, ao nos colocarmos no lugar de quem escreve, entre as tarefas de construir/organizar e apresentar um texto, e as referências modelares a que temos acesso - os textos "prontos".

Não conseguimos entender essa discrepância, e as interpretações se põem sobre dois problemas, a nosso ver: a mitologização do escritor como um "gênio" que começa a sua escrita e a termina, no tempo exato e linear do texto "pronto", e o conseqüente sentimento de fracasso e incompetência, com o qual nos deparamos, ao não reconhecermos, em nossos próprios processos de construção dos textos, esses elementos lineares, essa exatidão e a ausência dos percursos dos pesquisadores.

Há, a nosso ver, nessa linearidade comum a alguns textos acadêmicos convencionais, uma tentativa - bem sucedida - de apagamento dos rastros que revelam os caminhos percorridos pelos pesquisadores. Caminhos não lineares, onde muitas vezes anda-se em círculos, outras vezes toma-se desvios que dão em lugar nenhum. Caminhos que se alteram, no encontro com o inusitado, que muitas vezes sequer podemos explicar. Caminhos que são, em nosso entendimento, o próprio processo de construção do conhecimento. Esses rastros, reveladores da incompletude do conhecimento, da humanidade do pesquisador, da complexidade e polifonia dos múltiplos textos que compõem os textos, foram tomados, em determinado momento histórico, como excessos, como a bagunça que fica em nosso escritório e que deve ser "limpa", pois o produto final valorizado deve ser claro, objetivo, linear e econômico. 
E o que fazer, quando encontramos beleza e conhecimento nestes rastros? O que fazer quando, ao contrário de querermos "limpar" nossos rastros, compreendemos que esses são constitutivos do texto, enquanto processo vivo? Quando, ao insistirmos em manter aparente o percurso não linear pelo qual passamos, enquanto sujeitos que trilharam caminhos, repletos de encontros - alguns planejados, outros surpreendentes/ocasionais -, entendemos que o "produto final" não será o convencional?

Ao tomarmos por opção manter, no texto da pesquisa acadêmica que elaboramos, os rastros reveladores da historicidade da construção do texto, tornou-se necessário então dizer sobre o dito-feito. Isso significa assumir, mais que a complexidade do processo de construção, também nossos desencontros, nossas impotências temporárias, que foram inclusive motor dos caminhos renovados que tomamos também. Ou seja, assumir a encarnação de um sujeito que, ao deixar à mostra as pistas de seus caminhos e descaminhos, pretende justamente assumir a incompletude como condição de possibilidade do conhecimento.

Linguagens... mais que expressões, formas de organizar o mundo, elaboradas nestas formas de "dizer", no momento mesmo em que são "ditas". Dizer... forma historicamente posta da linguagem, reduzida ao falar/ouvir - oral, e mais tardiamente ao escrever/ler. Linguagem que se torna única e é levada, em sua dimensão epistemológica, ao "dizer" cercado e controlado - o "dizer" científico.

Aqui estamos nós, sujeitos numa era cujos dizeres, levados ao extremo da abstração e da neutralidade, já não dizem da complexidade do real, que não cessamos de compreender por múltiplas linguagens entendendo que a articulação entre esses dizeres e os fazeres é condição de compreensão da própria linguagem, como ação simbólica no mundo. E nesta "era de extremos", o lugar de onde "dizemos-fazemos", cercado e controlado, leva-nos muitas vezes a preferir mudar de lugar, a mudar as "ordens do dizer" dos lugares. Essa relação fica clara, para nós, quando contrapomos as formas do dizer-fazer de lugares diferentes.

Para nós, essa reflexão que aqui tecemos começou num momento que nos propiciou uma dupla leitura. Por um lado, nossa própria forma de dizer-fazer, na dissertação acadêmica ${ }^{1}$ que acabamos de tecer; por outro, a entrevista do diretor Walter Salles ao Caderno Mais!, da Folha de S. Pau$10{ }^{2}$ especificamente no momento em que este contrapõe a sua forma de dizer-fazer, enquanto cineasta, à forma do dizer-fazer da tese acadêmica.

Vamos inicialmente tentar dizer, aqui neste texto, da nossa própria forma de dizer-fazer, na elaboração de nossa dissertação, concordando com 
Walter Salles, quando este enuncia que "fazemos coisas que, ao serem ditas, e dependendo da maneira como são ditas, podem ganhar um sentido totalmente novo" (p. 8), portanto assumindo as reduções e implicações do dizer sobre o processo do dizer-fazer. A seguir, vamos tomar as formas do dizer-fazer do diretor de "Central do Brasil", para tentarmos entender o porquê dessa sua outra afirmativa, que deu origem à nossa reflexão:

É possível que aquilo que pensamos tenha a ver com algo que lemos, escutamos ou observamos em outros momentos. Mas isto não faz parte de um raciocínio apriorístico, do contrário o filme não seria o que é e sim a ilustração de uma tese de caráter acadêmico. Falar retrospectivamente de um filme é ordenar o que de início foi apenas uma soma de acasos e necessidades. (p. 8, grifos nossos.)

Assim, por termos que dar cabo de uma tarefa que nos incomodava em princípio, ou seja, ter que dizer sobre as formas do dizer-fazer, encontramos nesta afirmação de Walter Salles o motor que nos impeliu à tarefa, ao mesmo tempo que questionamos a distinção histórica dos lugares dos dizeres-fazeres. Longe de não reconhecermos as especificidades do cinema e da tese acadêmica, o que queremos é mostrar o quanto as linguagens, embora diferenciadas, possuem características que as aproximam, no processo de constituição destes dizeres-fazeres, colocando dessa forma a dicotomia não no lugar em si, mas na predição voluntária dos lugares, que se deu sócio-historicamente em nossa cultura moderna ocidental.

Iniciar uma pesquisa é, como o cineasta, colocar-se "na estrada". Esta estrada, para nós, tomou forma numa complexidade com/na qual interagimos, e que envolveu os textos "prontos" que já circulam nos meios acadêmicos e literários; as múltiplas interpretações e leituras destes textos, que transbordam o universo acadêmico e se derramam nos discursos do senso comum; os sujeitos a quem os textos focalizam, em sua dimensão silenciada, que buscamos resgatar a $v o z$ e potencializar enquanto sujeitos racionais. Já cabe dizer aqui de nossa pesquisa, e o faremos dizendo ao mesmo tempo de sua constituição, nesta estrada que não simplesmente percorremos. A metáfora da estrada tem um problema: não é caminho pelo qual se passa, de um ponto ao outro. É, antes, complexidade na qual se insere. Assim, nos pusemos na "estrada" mais como os andarilhos - "pardais" - que dela fazem sua "casa", ou seja, que nela se inserem e a percorrem não de passagem, mas como "parte da paisagem".

Iniciamos com um questionamento, que dizia respeito à relação entre a aquisição da escrita e desenvolvimento cognitivo de sujeitos adultos 
não-alfabetizados. Interessava-nos, desde o princípio, por essa relação (sub)entendida que exclui, historicamente, sujeitos não alfabetizados dos lugares da racionalidade e, ao mesmo tempo, buscávamos potencializar esses sujeitos como sujeitos racionais. Como, a um olhar mais atento, revelou-se uma discrepância entre as avaliações cognitivistas das pesquisas sobre o pensamento adulto não-alfabetizado e a observação concreta de suas existências no mundo. Assim, nos pusemos na "estrada", na interrelação entre as vozes dos pesquisadores do pensamento adulto nãoalfabetizado, de outros pesquisadores que fomos buscando, e as vozes dos próprios sujeitos das pesquisas. Nem sempre soubemos para onde estávamos indo. Por vezes, a impressão que tínhamos é de que estávamos andando em círculos, perseguindo o "nenhum lugar".

Um destes momentos foi quando das leituras sobre o desenvolvimento cognitivo de sujeitos não alfabetizados, juntamente com leituras dos estudos comparativos do desenvolvimento cognitivo de sujeitos de culturas diversas. ${ }^{3}$ Neste momento específico de nosso percurso, quando nos deparamos, nos limites, com espelhos que duplicavam ao infinito as questões, pensamos que era o "fim da linha". A ruptura veio com um olhar mais para trás das questões, tentando enxergar nos pressupostos e visões de mundo social e historicamente instituídos, a constituição de nosso próprio olhar, para a questão. Assim entendemos que, para atravessarmos a espessura dos espelhos que refletem nossa própria incapacidade de rompermos com as "ordens" que nos constituíram, enquanto sujeitos, seria preciso romper com essas ordens, ou seja, com nossa própria imagem refletida.

O que identificamos, como problemático, nas diversas pesquisas que estudamos sobre o desenvolvimento cognitivo dos adultos não-alfabetizados, foram justamente os critérios utilizados pelos pesquisadores, na identificação de desempenhos cognitivos avaliados como maior ou menor desenvolvimento cognitivo, por parte dos sujeitos da pesquisa. A análise destes critérios mostrou-nos que os desempenhos cognitivos eleitos como demonstrativos da legitimidade do raciocínio tinham seus fundamentos extraídos das leis da lógica formal. Pudemos ver esses critérios com clareza, na análise das tarefas propostas pelos pesquisadores e pelas avaliações das respostas às tarefas.

O que iniciamos foi, portanto, uma leitura crítica destas pesquisas e estudos, entendendo a inadequação da lógica formal no estudo do pensamento adulto não-alfabetizado, vislumbrando que estes critérios aproximavam o parâmetro ideal de racionalidade das pesquisas ao modelo da racionalidade moderna ocidental. 
Essa primeira ruptura, fundamental em nosso processo de elaboração da pesquisa, deixou-nos, por algum tempo, órfãos de referências. A resposta a nossa angústia - resposta essa que mais tarde também se revelaria problemática - "veio" a nós por um destes acasos que a "ciência" não incorpora. Um trabalho que chegou a nossas mãos ${ }^{4}$ apontava para uma outra gama de estudos, recentemente retomados, e que resgatavam, no âmbito da filosofia, uma outra lógica, diversa da formal, que os autores denominaram lógica discursiva, ou lógica da argumentação - a "Nova Retórica". Neste momento, investimos nesta perspectiva, acreditando que uma alternativa representava uma "brecha" que nos permitiria então caracterizar os sujeitos não-alfabetizados como racionais, pelos critérios da lógica discursiva.

Em nossa própria forma de dizer, passamos a buscar então lógicas, e não desempenhos cognitivos. Identificando a lógica formal como uma das formas lógicas possíveis, forma esta restrita ao universo dos lógicos-matemáticos, e também contrapondo-nos à forma da lógica demonstrativa, assumimos a perspectiva da argumentação enquanto a lógica do/no discurso.

Essa perspectiva nos permitiu um olhar outro para a nossa questão inicial, tanto que o título provisório que demos ao nosso trabalho de pesquisa se tornou, então: "O pensamento adulto não alfabetizado: da lógica formal à lógica discursiva". Neste momento, pela inserção neste universo de outras leituras, outro inusitado nos aconteceu: voltamos, sem premeditação, a uma das leituras dos estudos cognitivos - a pesquisa de Luria (1990): Desenvolvimento cognitivo: Seus fundamentos sociais e culturais. Ao (re)lermos as entrevistas que a equipe de pesquisadores de Luria desenvolveu nas regiões do Uzbequistão e Kirghzia, com adultos não-alfabetizados, encontramos nas vozes dos sujeitos da pesquisa formas lógicas que os pesquisadores não puderam reconhecer.

Fizemos, então uma primeira (re)leitura das entrevistas de Luria, utilizando como "chave de leitura" os estudos sobre a teoria da argumentação. Porém, ao mesmo tempo, iniciamos a análise da base de dados que originariamente havíamos escolhido para nossa pesquisa, em caráter exploratório: a análise de um diálogo, numa reunião de uma associação de moradores. O material de análise trata-se da transcrição de uma fita de vídeo, que focalizava uma reunião entre produtores rurais associados, da região do Bonfim, em Petrópolis, estado do Rio de Janeiro, e representantes do Instituto Brasileiro de Apoio ao Meio-Ambiente (Ibama), na discussão do tema que os envolvia: a desapropriação das terras dos 
produtores, por motivo de um decreto do governo federal, que declarava as terras do Bonfim área do Parque Nacional da Serra dos Órgãos. Tentávamos, então, utilizando os critérios da lógica discursiva, analisar as lógicas confrontadas nas discussões entre os sujeitos participantes da reunião do Bonfim. Além das referências teóricas da argumentação, já trabalhávamos com a perspectiva teórica de Bakhtin (1987).

Mas as inadequações da teoria da argumentação se revelavam mais fortes, a cada momento. Inadequações que por vezes se nos apresentam como sensações de "mal-estar", suspeitas que temos, indisposições que não nos permitem mergulhar fundo na perspectiva. Clara para nós ficou a inadequação central que nos levou a buscar outros diálogos, na oportunidade que tivemos de apresentar os resultados parciais da pesquisa, num seminário organizado pelo grupo de orientação. Neste seminário, quatro professores, além da orientadora, foram convidados para conosco discutir a pesquisa.

A partir da discussão que neste seminário se estabeleceu, foi-nos revelada a fonte de nossa inquietação: apesar da lógica discursiva ser uma alternativa aos estudos cognitivos, que tinham como critério de análise a lógica formal, esta teoria apresentava uma outra forma lógica possível, mas também universal. E, com Bakhtin e Ginzburg (1991), compartilhamos de uma outra visão da racionalidade. Entendemos que a racionalidade ocidental moderna se constituiu sobre a crença na forma única da racionalidade cognitivo-instrumental, tendo como modelo e referência a forma da racionalidade da sua própria cultura. Os âmbitos restritos dessa racionalidade única e universal somente reconhecem como racionais os seres que compartilham destas formas de organização do real. Formas outras de pensar/agir/ dizer são apontadas como déficits de razão. Ao contrário, acreditamos que as racionalidades são múltiplas. $O$ que nos faltava era o elemento organizador que desse sentido a essa multiplicidade. Olhar para a cultura em que os sujeitos estão inseridos e que modificam, em suas existências, nos deu esse sentido do olhar. Ao mesmo tempo, nos permitiu identificar as limitações da teoria da argumentação: não rompendo com o pensamento que crê numa racionalidade universal, mantém, em conseqüência, pressupostos que levam os autores a crer em ser possível um olhar para os sujeitos desvinculados das suas culturas. Ao revermos criticamente a teoria da argumentação, entendemos que esta trata da racionalidade que se expressa na ação discursiva. Assim, entendemos a inadequação que nos incomodava: as relações interativas entre os sujeitos não se reduzem à interação discursiva. As linguagens, como as racionalidades, também são múltiplas, e as formas do discurso não esgotam as possibilidades das racionalidades. 
Ao voltarmos às nossas bases de dados - a (re)leitura de Luria e o diálogo do Bonfim - vimos fazer sentido então um universo de possibilidades outras. Ao compreendermos a relação inseparável entre as racionalidades, as linguagens e as culturas, pudemos encontrar então, inclusive, o sentido renovado das referências teóricas de Bakhtin e Ginzburg. Assim, pudemos entender o que Bakhtin (1981) nos diz quando afirma que "o pensamento do sujeito é inacessível ao enfoque objetificante" e que, o que é possível fazer, é com que o sujeito revele seu pensamento, pela/na ação dialógica. Nas enunciações, na qual o sujeito expressa-se como voz, podemos buscar indícios de uma realidade inacessível à observação: indícios de suas formas de organização do real, de suas racionalidades, que acreditamos serem intimamente relacionadas com suas vivências, práticas e relações pela/na cultura.

Assim, as vozes dos sujeitos da pesquisa de Luria e dos sujeitos do diálogo do Bonfim nos revelaram formas racionais complexas, que de maneira indiciária pudemos relacionar com suas formas de ser nas culturas. Já aqui não falávamos mais de lógicas. O termo, modificado nas interações, torna-se para nós racionalidades, no plural, em contraste com uma racionalidade única, onde o diverso não tem lugar - pelo menos não um lugar enquanto também.

Como, a partir destes múltiplos olhares, organizados e (re)organizados na polifonia dos múltiplos diálogos, podemos desconsiderar o processo que vivemos? Acreditamos que essa estrada que nosso trabalho percorreu é também o nosso trabalho. Percurso e texto formam uma unidade dialética que, ao fim ou centro, nos põe de volta no lugar de origem, mas com outros olhares para as questões. Desta forma, e porque o caminho ainda não foi de todo percorrido, é que os rastros têm de ficar, de estar à mostra. Não é "bagunça", nem excesso: é o trabaIho mesmo, é o processo. Optamos então por manter os rastros. Tanto que o leitor se espanta pela "dança" das palavras que tomam propositadamente, no decorrer do trabalho feito texto, formas diferenciadas. Cognição, lógica ou racionalidades? Num momento, cognição. Depois, lógica/lógicas, para depois racionalidades/formas de organização do real. Diálogo, num sentido, depois em outro. Foi assim que, nos múltiplos encontros na estrada, organizamos nossas próprias formas de olhar para as questões. Mudando. Abrindo. Compreendendo, pelas/nas relações.

E a forma da escrita, com textos "inteiros" postos uns ao lado dos outros, menos capítulos que uma "colagem" de fragmentos, revela pou- 
co da forma como foram escritos. Não havia apresentação possível que se mantivesse fiel ao tempo real de suas escritas. A organização final foi isso mesmo: organizativa, para permitir ao leitor uma leitura que mais ou menos se desenvolve num sentido. Mas o primeiro texto foi talvez o terceiro a ser escrito, o último talvez o quarto, como saber? Como é mesmo o tempo do conhecimento na complexidade do mundo?

Dizer sobre o dito-feito é, como diz Walter Salles, abrir-se aos novos sentidos. Não é tarefa que tememos, já que aprendemos, no processo de construção do trabalho de pesquisa, que é assim, aberto, incompleto e complexo o conhecimento, já que ele se dá pelo/no encontro dialógico. Mas vamos ouvir Walter Salles, em sua entrevista para o caderno Mais!, da Folha de S. Paulo, para entendermos a aproximação que gostaríamos de marcar. Em primeiro lugar, a pergunta se faz necessária: por que essa aproximação? A resposta é simples: porque nos reconhecemos, ou seja, reconhecemos, nas palavras de Walter Salles, elementos que julgamos similares ao nosso próprio processo de construção da dissertação acadêmica. Mas, mais que isso, porque fomos provocadas pela afirmação do cineasta, quando este distingue o filme da tese acadêmica, justamente no momento em que, na descrição do processo de construção do filme, reconhecemos similitudes ao nosso processo de construção da tese acadêmica.

O que vamos fazer é recolher, da entrevista de Walter Salles, as falas nas quais vimos as similitudes que gostaríamos de marcar. Em primeiro lugar, a idéia inicial, deflagradora da obra. Para o cineasta, tudo teve início a partir da forte impressão que teve, diante de uma constatação: como a troca de cartas é "decisiva na vida das pessoas". O que ele faz então é pensar o avesso da questão: imaginar a interdição da circulação das cartas, como interdição das vozes das pessoas. Focalizar, então, a idéia, não pelo fato em si, mas em seu avesso, criando assim uma ruptura fundadora.

Nos reconhecemos, pois nossa ruptura inicial se deu a partir da inversão do olhar, no momento em que os espelhos eram o limite das pesquisas sobre o pensamento do adulto não-alfabetizado. Ao invés de olhar para o que estava posto - a "incapacidade" cognitiva tradicionalmente marcada -, olhamos então para o "analfabetismo" como forma de ser outra coisa, ou seja, buscamos o que estaria "vivo" neste "não ler", enquanto formas racionais que estivessem relacionadas a outras formas culturais. A fundação se deu na capacidade de ruptura com o exterior visível, abordando o seu avesso. Essa torção do olhar possibilitou o caminho. 
Em relação aos instantes do processo, Walter Salles nos dá uma definição, na forma de uma metáfora: "Como numa ordem sinfônica, cada plano é grávido do próximo plano, assim como cada nota anuncia a nota seguinte." (p. 7).

Tanto pelo aspecto dos planos interrelacionados, que se desenvolvem a partir/nos anteriores, como se cada passo na realidade já antecipasse o próximo, trazendo em si e em sua existência a semente do outro, quanto pela analogia à ordem sinfônica, a metáfora é belíssima. Talvez possamos acrescentar que é bela porque a ordem sinfônica é polifônica, e acreditamos que justamente estas múltiplas vozes, em seus encontros, é que engravidam o instante dos instantes que ele funda. Porque cada instante é aberto e clama pelo próximo; próximo este que traz em si os que o antecederam, num processo genético - onde tradição e necessidade do novo formam uma unidade dialética e complexa, mas não gradual.

Assim é o processo da construção do texto: polifônico, que tem como unidade temporal o instante, este mesmo parte de uma complexidade dentro da qual faz sentido. Os textos estão sempre "grávidos" de outros textos, tendo vindo da multiplicidade dos textos que são, na realidade, o contexto nos quais se fundam. Essa é nossa visão do texto acadêmico, que se fez no processo de inserção na (con)textualidade, e que nos aponta para os textos que precisam ainda ser escritos, já anunciados nos que já escrevemos.

Walter Salles nos diz também da marca do cinema brasileiro contemporâneo, onde cada filme não tem valor paradigmático. Na realidade, é justamente a pluralidade a marca que o torna tão bom. Na negativa ao gênero, temos uma pluralidade de formas, que se assemelham no desejo de falar de Brasil, de diversas formas. Aqui a riqueza dos múltiplos olhares, como na fotografia contemporânea. Ao mesmo tempo, nos aponta para a complexidade, e para a árdua tarefa que temos que dar conta, que é justamente a possibilidade da compreensão do real, a partir dos múltiplos olhares, expressos pelas múltiplas linguagens. Tarefa onde o singular, o pequeno, traz em si e nos permite ver, reflexivamente, o macro, o complexo.

O diretor de Central do Brasil termina sua entrevista, respondendo a uma pergunta emblemática: "O que alguém que 'pensa em imagens' sente quando é solicitado a 'pensar em palavras'?" Inevitável pensarmos em Abbas Kiarostami, como Walter Salles também o fez, citando-o para dizer que "muito do que fazemos é da ordem do inexplicável". Lembramos Kiarostami, mas lembramos do que este fez, dizendo em palavras 
daquilo que ele mesmo viu e certamente "pensou em imagens", expresso no belíssimo texto "Uma boa boa cidadã" ${ }^{5}$ O resultado do texto foi exatamente isso: um texto em que as imagens do cotidiano, percebidas pelo olhar acurado do cineasta, nos ensinam a escrever e pensar a realidade, a partir do "pequeno", do "imperceptível" aos olhos acostumados da nossa cultura. Nos ensinam a fazer do realismo uma ponte para o poético, como diz Salles, citando Pabst.

Mas o que responde o cineasta, citando Kiarostami, é aquilo que precisamos incorporar, na academia. Assumir o inexplicável - e aí nos lembra Ginzburg, dizendo sobre as "sutilezas não formalizáveis" do paradigma indiciário - como constituinte dos fazeres-dizeres. Acolher/ resgatar a intuição como constitutiva do conhecimento, assumindo não se ter exatidão dos "como" e dos "porquês" com os quais se chega aos lugares que chegamos.

E assim, entender que o "falar" sobre o "feito" é, de fato, a ordenação, no relato, da "soma dos acasos e necessidades" que constituíram o processo do fazer. Significa incorporar esses elementos que a ciência moderna relegou aos lugares heréticos, e assumir como compromisso o desejo de falar do que nos implora a voz: o silenciado, o negligenciado, o "imperceptível". Como a menina de andar digno, de Kiarostami, como a redescoberta da humanidade, de Salles, como nosso próprio desejo: a legitimidade da racionalidade dos não-alfabetizados.

Em nosso trabalho de dissertação, o mais difícil foi, sem dúvida, relatar o processo. Buscar na rememoração os procedimentos, os desvios, os modos de fazer, encontra eco na afirmação final de Salles, na entrevista. Citá-lo é quase que descrever nosso próprio processo:

Tudo isto faz parte do trabalho da memória que procura reunir a pluralidade que deu forma ao todo não completamente previsível em seu começo e em seu resultado final. Sobretudo em se tratando de um "filme de estrada", que é uma matéria viva, pronta a renovar-se e a remodelar-se, em função das surpresas que encontramos e da inventividade de todos os que colaboraram em sua realização. (Mais!, p. 8)

Mais que desejar simplesmente nos aproximarmos do cineasta, o que entendemos, nesta aproximação, é que Bakhtin estava correto quando dizia sobre a circularidade dos conhecimentos. O que vemos são indícios de um outro paradigma, que rompe com a modernidade, que começa a ser desenhado e que, circulando na cultura, marca os fazeres huma- 
nos. As similitudes estão, então, menos nos fazeres - já que as linguagens são diferenciadas - e mais nos pressupostos que guiam esses fazeres.

Assistir ao filme Central do Brasil é esbarrar, durante quase todo o tempo, com os rastros que Walter Salles deixa, e que fazem pleno sentido ao ouvirmos suas palavras. Aqui encontramos mais uma das riquezas de seu trabalho: os vestígios da construção do filme estão lá, prontos a serem lidos pelo olhar indiciário. Entender isso reafirma nossa própria opção e nos insere num universo de possibilidades: somos todos parte de um movimento que professa a pobreza da era da qual somos herdeiros neste fim de século, como nos pede Benjamin, mas que tenta resgatar a riqueza e a aura dos fazeres humanos; assumindo a diversidade dos olhares e das linguagens e tornando possível as rupturas com as ordens do dizer-fazer, dos diversos lugares do dizer-fazer. O lugar da academia tem, sim, tradicionalmente, uma bagagem carregada de crenças e pressupostos cultivados no contexto da era moderna, mas que não podem ser tomados como expressão característica e una do dizer-fazer do seu lugar, de seus sujeitos. As rupturas acontecem onde acontece a linguagem, impregnando os fazeres com as mudanças paradigmáticas que, aliás, estas linguagens contribuem para construir e desconstruir, historicamente.

Acreditamos encontrar um pouco a aura perdida na abertura do texto acadêmico ao reencontro com a poesia, ao mesmo tempo em que na ação de deixar à mostra os rastros de nosso percurso, que acreditamos serem possibilitadores da tradição, pela reconstrução das narrativas da experiência. Além disso, pelas (re)leituras múltiplas e diversas que se tornam possíveis por meio dos vestígios e indícios que deixamos, pistas de nossas estadas/estradas, experiências espalhadas no processo, que nos deixam à mostra, que nos vinculam indissociavelmente aos nossos fazeres. Resgatar, como diz Benjamin, a humanidade, o vínculo entre os homens e mulheres e seus fazeres, tentando sobreviver/resistir à ordem da cultura que mandou que se apagassem todos os rastros.

Recebido para publicação em 8 de agosto de 1998.

\section{Notas}

1. "A multiplicidade das formas de ser racional: Escrita e racionalidade." Dissertação apresentada ao Programa de Pós-Graduação em Educação da Universidade Federal Fluminense (UFF), e aprovada em março de 1998, como requisito parcial para obtenção do grau de Mestre. 
2. Jornal Folha de S. Paulo, domingo, 29 mar. 1998, Caderno Mais!, p. 7-8.

3. Os estudos cognitivos a que nos referimos pertencem a uma gama de autores que têm, como referências teóricas, principalmente os estudos piagetianos e vigotskianos. Os estudos interculturais podem ser encontrados nos artigos e referências bibliográficas de Olson, D. \& Torrance, N. Cultura escrita e oralidade, São Paulo: Ática, 1995.

4. Perelman \& Olbrechts-Tyteca (1996).

5. Publicado no caderno Mais! da Folha de S. Paulo, em 11 de janeiro de 1988, p. 4-6.

\section{Traces: SPEAKING ABOUT FORMS OF DOIG-SAYING}

ABSTRACT: This paper aims at contributing to the development of a new paradigm in the social sciences. To do so, it attempts to clarify notions inherited - and maybe wrongly misinterpreted in the process - from the social and historical context of modern western culture. The notions to be clarified are related to one of modern western culture's projects, namely, the "obliteration" of the subject and the establishing of differences between subjects and their many ways of doing, saying and thinking. The paper reports on the process of developing our own research work and articulates it with a reflection about the several ways of doing-saying. It builds on a possible approximation between academically acceptable processes of doing-saying and the account, by the film director Walter Salles, of his making of the movie Central do Brasil. Finally, it emphasizes the view that links people to their doings and sayings, understood as "traces" that remain - and thus allow us to reconstruct the processes through marks - and that we legitimate, as constitutive parts of the doings and sayings associated with the many rationalities intimately linked to people's experiences and practices in/through culture.

Key words: Traces, Languages, Culture, Illiterate adults, Knowledge.

\section{Referências bibliográficas}

BAKHTIN, M.M. A cultura popular na Idade Média e no Renascimento: O contexto de François Rabelais. São Paulo: Hucitec; Brasília: Editora da UnB, 1987.

. Problemas da poética de Dostoiévski. Rio de Janeiro: Forense Universitária, 1981. 
BENJAMIN, W. Magia e técnica, arte e política: Ensaios sobre literatura e história da cultura. Obras Escolhidas, vol. 1, São Paulo: Brasiliense, 1994.

CERTEAU, M. A invenção do cotidiano: Artes de fazer. Petrópolis: Vozes, 1994. GINZBURG, C. Mitos, emblemas e sinais: Morfologia e história. São Paulo: Companhia das Letras, 1991.

LURIA, A.R. Desenvolvimento cognitivo: Seus fundamentos culturais e sociais. São Paulo: Ícone, 1990.

PERELMAN, C. \& OLBRECHTS-TYTECA, L. Tratado da argumentação: $A$ nova retórica. São Paulo: Martins Fontes, 1996. 